\title{
Protein-species quantitative venomics: looking through a crystal ball
}

\author{
Juan J. Calvete ${ }^{1^{*}}$, Daniel Petras ${ }^{2}$, Francisco Calderón-Celis ${ }^{3}$, Bruno Lomonte ${ }^{4}$, Jorge Ruiz Encinar ${ }^{3}$ \\ and Alfredo Sanz-Medel ${ }^{3}$
}

\begin{abstract}
In this paper we discuss recent significant developments in the field of venom research, specifically the emergence of top-down proteomic applications that allow achieving compositional resolution at the level of the protein species present in the venom, and the absolute quantification of the venom proteins (the term "protein species" is used here to refer to all the different molecular forms in which a protein can be found. Please consult the special issue of Jornal of Proteomics "Towards deciphering proteomes via the proteoform, protein speciation, moonlighting and protein code concepts" published in 2016, vol. 134, pages 1-202). Challenges remain to be solved in order to achieve a compact and automated platform with which to routinely carry out comprehensive quantitative analysis of all toxins present in a venom. This short essay reflects the authors' view of the immediate future in this direction for the proteomic analysis of venoms, particularly of snakes.
\end{abstract}

Keywords: Snake venomics, Top-down proteomics, Top-down venomics, Protein species-resolved venomics, Absolute quantification, Inductively coupled plasma mass spectrometry

\section{Background}

Rooted in a tradition of observation and description dating back at least to Aristotle, the study of natural phenomena (natural philosophy) involved for much of its history qualitative reasoning and explanations about nature. Aristotle's conception of nature prevailed from the Middle Ages until the modern era. The precursor of modern science developed from natural philosophy with the introduction of the experimental method to make objective observations that can be verified by others as true or false. This approach was advocated by the Tuscan polymath Galileo Galilei (1564-1642) in 1638 with the publication of Two New Sciences. Galileo [1] revolutionized observational astronomy with his introduction and use of the telescope [2, 3]. Albert Einstein and Stephen Hawkins considered Galileo "the father of modern observational science", as he based his science on careful observations, measurements, and controlled experiments. "The book of nature is written

\footnotetext{
* Correspondence: jcalvete@ibv.csic.es

${ }^{1}$ Structural and Functional Venomics Laboratory, Instituto de Biomedicina de Valencia, C.S.I.C, Jaime Roig 11, 46010 Valencia, Spain

Full list of author information is available at the end of the article
}

in the language of mathematics" is probably the most well-known genuine quote from Galileo Galilei. The scientific method exemplifies a mathematical understanding of nature that is the hallmark of modern natural scientists. Only by means of quantitative measurements can one arrive at the formulation of hypotheses and theories that account for the causal relationships or associations of the elements of a system.

Recent advances in high-throughput sequencing and mass spectrometry technologies have shifted the focus in biology from the measuring of a single protein, complex or pathway to the comprehensive analysis of all cellular components and their dynamic crosstalk. Beyond identification, it is important in most biological studies to know the quantity of a protein present in a sample. Although a single analytical method is usually insufficient to unravel in detail the complexity of living systems, perhaps the technical and conceptual framework that comes closest to this goal is mass spectrometry-based proteomics [4].

Established in the 1990s as a powerful though qualitative analytical technique [5-7], proteomics has undergone a revolution, and novel technologies for the systematic quantitative analysis of proteins have emerged 
coinciding with the turn of the century [8] and over the first decade of the XXI century [9]. These approaches have expanded our ability to acquire information from single proteins to proteomes, and promise that proteomes will soon be studied at a similar level of dynamic resolution as has been the norm for genome-wide gene expression using RNA microarrays and next-generation sequencing [10]. Label-free approaches have been applied to quantify snake venom proteomes [11, 12]. However, mass spectrometry is not inherently quantitative because of differences in the ionization efficiency and/or detectability of the many peptides in a given sample. This analytical limitation has sparked the development of methods to determine relative and absolute abundance of proteins in samples $[9,13]$.

\section{Peptide-centric mass spectrometry-based relative quantification}

Mass spectrometry-based relative quantification techniques can be divided into two general categories: those that operate label-free, in which spectral counting or ion-intensity determinations of surrogate proteolyticallyderived peptides represent a measure of the parent protein abundances [14], and those that use isotope-based methods for the comparative analysis of differential chemically or metabolically isotope-tagged proteomes [15]. Isotope-based methods incorporate heavy versions of specific molecules into the peptides, either by chemical derivatization or by metabolic labeling. Depending on the chemical derivatization technique employed, the differentially labelled peptides are quantified in MS or MS/MS mode [9, 16-24]. Thus, non-isobaric isotopecoded affinity tag (ICAT)-labeled peptides, metal-coded (MeCAT)-tagged peptides, residue-specific-tagged peptides such as ${ }^{13} \mathrm{C} /{ }^{15} \mathrm{~N}$ dimethyl labeling of $\mathrm{N}$-termini and $\varepsilon$-amino groups of lysine, and $\mathrm{O}^{16} / \mathrm{O}^{18}$ labelled peptides can be adequately quantified by MS.

On the other hand, peptides derivatized with isobaric tag for relative and absolute quantification (iTRAQ) or with isotopomer "tandem mass tags" (TMTs) require tandem MS-level quantification. These peptide-centric approaches are mainly used to quantify relative differences in peak intensity of the same analyte between multiple samples. Applications to venomics has been so far scarce, including the relative quantification of type A and type B venoms from the same species of $C$. s. scutulatus and the venoms from two geographically unrelated snakes from North and South America, C. o. helleri and B. colombiensis, respectively [25]. More recently, the comparative analyses of venom during the neonate-to-adult transition of Bothrops jararaca [26] and Gloydius brevicaudus were carried out [27].

The metabolic method stable isotope-labeling of amino acids in culture (SILAC) provides a powerful experimental strategy in certain circumstances (proteomic studies in cultured cell lines; in vivo quantitative proteomic using SILAC mice) [28]. However, it may not represent a feasible option when working with protein samples, such as venoms isolated from organisms that are not amenable to metabolic labeling.

\section{Isotope dilution mass spectrometry-based absolute quantification}

Molecular mass spectrometry approaches using isotopic labeling have been extensively used over the last 15 years to quantify relative differences between a limited number of samples. However, transformation of the intensity signal ratios into absolute concentration values requires the use of species-specific internal calibration standards of controlled composition and certified concentration. Absolute proteomic quantification using isotopic peptides entails spiking known concentrations of synthetic, heavy isotopologues (e.g. AQUA-absolute quantification-peptides; QconCAT-quantification concatamer) of the proteotypic target peptides into an experimental sample, before the digestion step, to determine the intensity ratio (isotope dilution) of spiked and target peptides by LC-MS or LC-MS/MS [29-33]. The abundance of the target peptide in the experimental sample is back calculated to the initial concentration of the standard using a pre-determined standard curve to yield the absolute quantification of the target peptide.

Analytical application of the radiotracer method represents the forerunner of isotope dilution. This method was developed in the early $20^{\text {th }}$ century by the Hungarian chemist George de Hevesy [34], for which he was awarded the Nobel Prize in Chemistry in 1943. Isotope dilution mass spectrometry is a direct ratio method that has been identified by the Consultative Committee for Amount of Substance (CCQM) of the International Committee for Weights and Measures (CIPM) to have the potential to be a primary method. Scanning modes available in tandem mass analyzers, such as selected reaction monitoring (SRM) and parallel reaction monitoring (PRM), can be applied to targeted proteomic workflows in combination with isotopically-labeled versions of proteotypic peptides, which uniquely represent target proteins or a protein isoform, to monitor a selection of proteins of interest with high sensitivity, reproducibility and quantitative accuracy [35-39]. However, these methods are very laborious and costly, as they require the synthesis and characterization of at least one individual isotopic standard for each target protein, making targeted proteomic approaches impractical, particularly in venom analysis. A possible alternative to overcome these limitations is a well-known technique in the field of bioinorganic analysis: inductive coupled plasma mass 
spectrometry (ICP-MS) combined with stable-isotope dilution. Figure 1 illustrates the principle of isotope dilution for absolute quantification.

\section{ICP-MS}

ICP-MS is a type of elemental mass spectrometry introduced by Houk et al. [40] in 1980. Commercially introduced soon after 1983 for elemental determinations, ICP-MS has become the most powerful analytical tool for tracing elemental analysis, enabling robust determinations of metals, semimetals and several nonmetals (and their different isotopes) at concentration levels as low as one part in $10^{15}$ (part per quadrillion, ppq) using adequate non-interfered low-background isotopes [41]
(Fig. 2). This is achieved by atomizing and ionizing the sample in a "hard" ion source, inductively coupled argon plasma. Once the elemental ions from the sample enter the mass spectrometer, they are separated by their massto-charge ratio. The most commonly used type of mass spectrometer is the quadrupole $(\mathrm{Q})$ mass filter.

The potential of ICP-MS for screening simultaneously multiple metals, semimetals and biologically important nonmetals (e.g., S, P, I), naturally occurring in proteins, and its capability of achieving absolute protein quantifications via determinations of heteroatoms have been reviewed [42, 43]. Among these elements, sulfur results of particular relevance in proteomics (and specifically in venomics). Incorporated into the
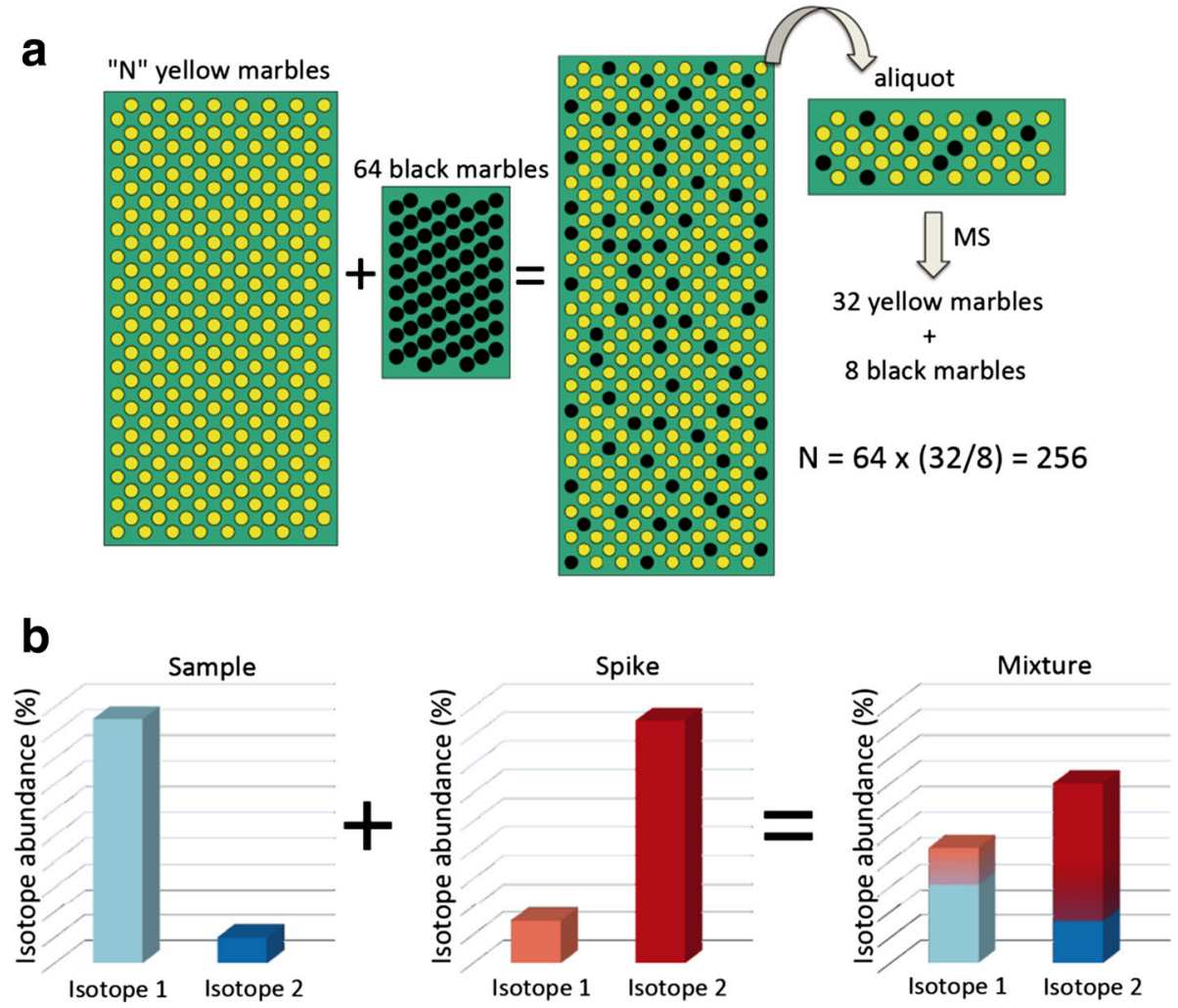

$$
N_{S}=N_{s p} \cdot \frac{R_{m} \cdot A_{s p}^{2}-A_{s p}^{1}}{A_{s}^{1}-R_{m} \cdot A_{s}^{2}}
$$

Fig. 1 The principle of isotope dilution. a Simplified cartoon (adapted from Alonso and González [33]) illustrating the principle of absolute quantification by dilution. The addition of a known amount of an internal standard (black marbles) to a sample containing an unknown ( $\mathrm{N}$ ) number of an analyte (yellow marbles) changes the concentration of the analyte. By determining the ratio of internal standard to unknown analyte in the resulting mixture, it is possible to back-calculate the amount of the analyte present in the sample. $\mathbf{b}$ A more complex situation arises in isotope dilution analysis when the sample, of natural isotopic composition, is mixed with an isotopically enriched spike. The image illustrates an example for an element containing two different isotopes ( 1 and 2). The resulting isotopic composition of the mixture to be measured is the combination of the sample's and spike's individual isotopic compositions and their molar ratios because the moles of the element in the mixture is the sum of the moles coming from the sample and the spike. If the number of moles added with the spike $\left(\mathrm{N}_{\mathrm{sp}}\right)$, as well as the isotopic composition of sample and spike (abundances of the isotopes 1 and 2 in the sample and spike: $A_{s}^{1}, A_{s}^{2}$ and $A_{s p,}^{1} A_{s p \text {, }}^{2}$ respectively) are known, it is hence possible to determine the number of moles of the element in the sample $\left(\mathrm{N}_{\mathrm{s}}\right)$ from the measurement of a single isotope ratio in the mixture $\left(\mathrm{R}_{\mathrm{m}}\right)$ 


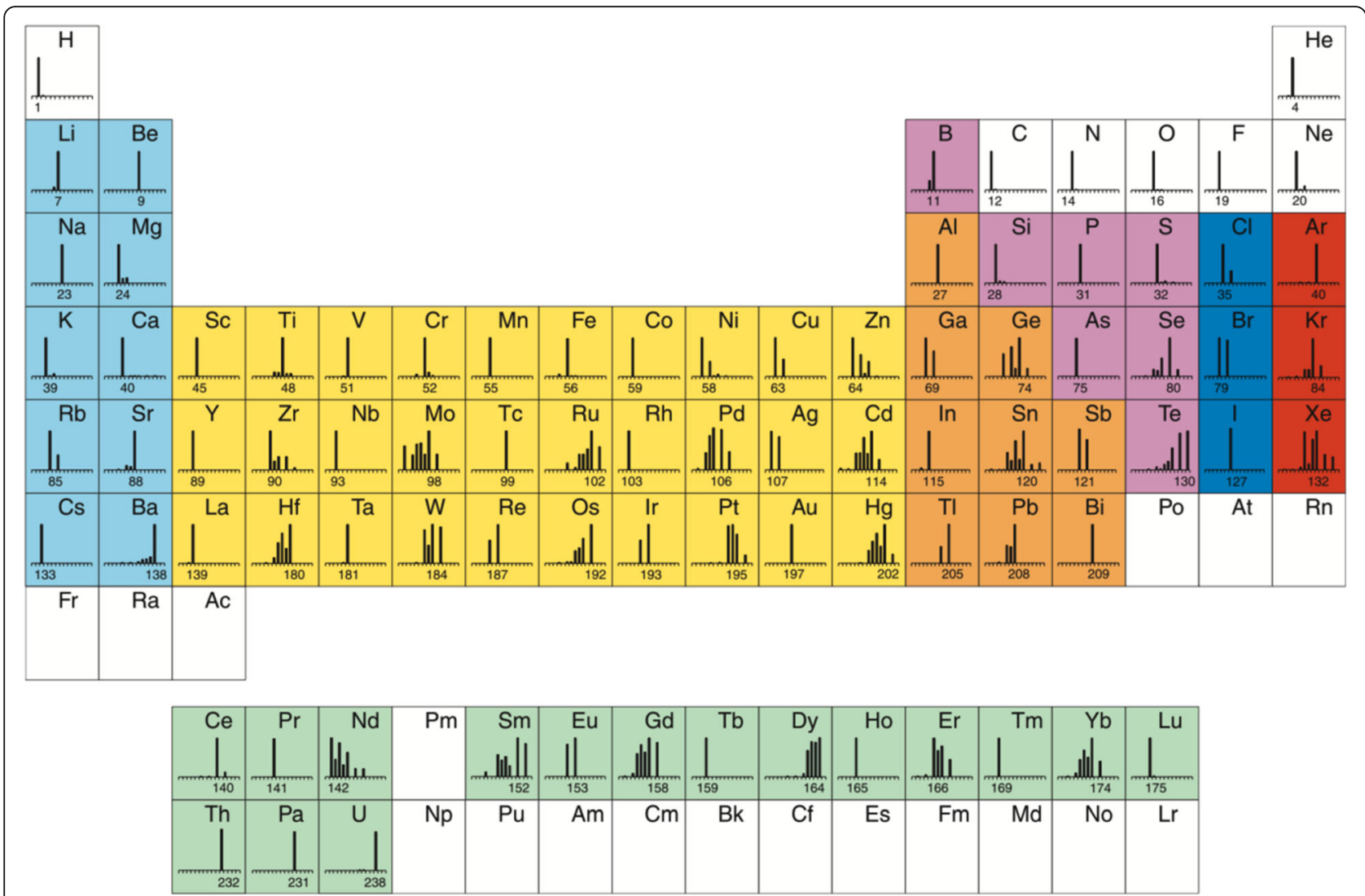

Fig. 2 Color-coded groups of elements traditionally determined by ICP-MS (courtesy of PerkinElmer, Inc.). Light blue, alkali earth and alkaline earth; yellow, transition metals; orange, other metals; magenta, metalloids; dark blue, halogens; red, noble gases; pale green, rare earth elements of the Lanthanide and Actinide series

amino acids methionine and cysteine, the element sulfur is present in almost all toxin classes, particularly in small proteins whose global folds are stabilized primarily by the formation of disulfide bonds [44]. Mass spectrometric determination of cysteine (in $\mathrm{SH}$ and $\mathrm{S}-\mathrm{S}$ forms) content represents a useful proxy for the preliminary classification of toxins into protein families [45].

The omnipresence of sulfur in venom proteins, and the fact that they can be efficiently separated by reversed-phase high-performance liquid chromatography (RP-HPLC), makes the absolute protein quantification using sulfur analysis by ICP-MS feasible. The main advantage of this approach is that only one generic sulfur-containing standard (i.e., one isotopically labeled sulfur spike such as ${ }^{34} \mathrm{~S}$-sulphate) is required to quantify each and all proteins of a venom proteome provided that they are completely separated and their amino acid sequences are known [46]. Moreover, the recent introduction of the tandem ICP-MS concept (triple quadrupole QQQ mass analyzer) enabled limits of detection (LODs) in the low femtomole range for S-containing peptides/proteins [47]. Of course, peak purity is here a pre-requisite as ICP-MS-based elemental detection cannot distinguish if sulfur comes from one or another protein or another compound present in the sample.

Moreover, the amino acid sequence information and sulfur/protein stoichiometry are needed to transform the total ICP-MS measured peak sulfur mass content into intact protein concentration (e.g., as moles of toxin per gram of venom). This way of expressing the data has more biological sense than " $\mathrm{g}$ of toxin/g of total venom proteins" derived by monitoring the RP-HPLC eluate with UV-VIS at $215 \mathrm{~nm}$, since the number of toxic molecules, rather than their mass, is responsible for the biological effects of the venom.

Very recently, Calderón-Celis et al. [48] have reported the application of RP- $\mu$ HPLC-ICP-QQQ and on-line ${ }^{34} \mathrm{~S}$ isotope dilution analysis for the absolute quantitative analysis of the major toxins comprising the venom proteome of the Mozambique spitting cobra, Naja mossambica. Identification of the toxins eluting along the chromatographic separation was carried out by ESI-MS mass profiling in parallel to the ICP-MS measurements, matching the recorded isotope-averaged molecular masses to the calculated masses for mature Naja spp. proteins deposited in the non-redundant NCBI database 
and to N. mossambica venom proteins previously identified by peptide-centric venomic analysis [49]. The results indicated that elemental MS, via tandem ICP-MS (QQQ) represents a direct and accurate methodology for absolute quantification of venom proteomes. A schematic of this hybrid (molecular and elemental) workflow is displayed in Fig. 3.

A note of caution: this approach works well for proteins without unpredictable PTMs, as is the case of the major toxins of many species of elapids (such as 3FTxs, PLA ${ }_{2} \mathrm{~s}$, Kunitz-fold proteins, cysteine-rich secretory proteins, C-type lectin-like proteins), but may be impracticable for other proteins, eg. toxins bearing complex PTMs as glycosylation (i.e. snake venom metalloproteinases, snake venom serine proteinases). Identification of these proteins should be based on internal sequence determination, usually performed using bottom-up MS/MS approaches.

The trend towards hybrid configurations of mass analyzers has dominated recent advances in instrumentation. Hybrid mass spectrometry systems use various designs of in-space beam-type and in-time ion-trapping spectrometers to combine the different performance characteristics offered by the individual mass analyzers into one instrument. The incorporation of ICP-MS into current and novel mass spectrometry workflows may open the door to a synergistic pair's work. That is, a judicious combination of elemental and molecular MS approaches could provide enhanced robustness, sensitivity, analytical speed and overall performance through the parallel identification and absolute quantification of heteroatom-bearing peptides and proteins.

\section{Top-down venomics}

Bottom-up venomics platforms (outlined in the study by Lomonte et al. [50]) usually provide incomplete protein sequence coverage, not allowing distinguishing between different protein species, particularly proteoforms or closely related isoforms of toxin family members [51-53]. In addition, proteolytic digestion eliminates the connectivity between intact proteins and the tryptic peptides they yield, complicating computational analysis and biological interpretations. To a certain extent, locus-specific assignments can be achieved by using an homologous snake venom gland transcriptome as a database for the assignment of mass spectra [54, 55].

Top-down mass spectrometry has the potential to eliminate the shortcomings of bottom-up workflows [56, 57]. Top-down MS is typically performed on Fourier-transform ion trap mass spectrometers, which offer the ultra-high mass resolution needed to achieve isotope resolution for charged state determinations of fragment ions in MS/MS experiments. Our typical top-down venomics workflow involves: front-end fractionation of complex disulfide-bond-reduced protein

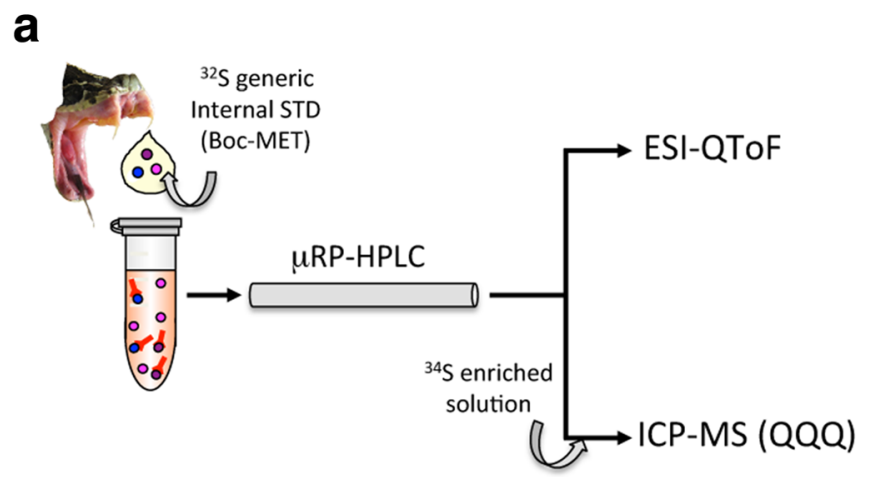

C

$$
C_{S}=C_{S p} \frac{W_{S p}}{W_{S}} \frac{A w_{S}}{A w_{S p}} \frac{A_{S p}^{a}}{A_{S}^{b}} \frac{R_{M}-R_{S p}}{1-R_{M} R_{S}}
$$

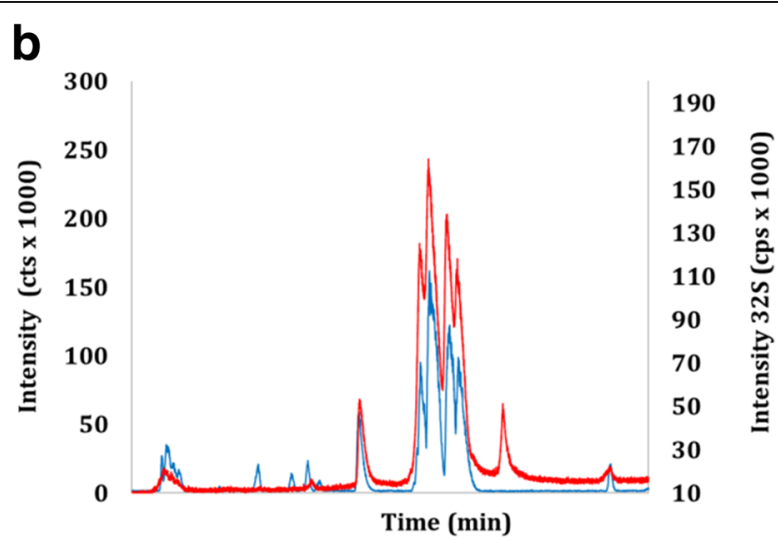

Time (min)

Fig. 3 a Scheme of the parallel hybrid RP- $\mu$ HPLC-ICP-QQQ with on-line ${ }^{34}$ S isotope dilution and LC-ESI-QToF analyses for the absolute quantitative analysis of the major toxins identified by mass profiling in the venom of the Mozambique spitting cobra, Naja mossambica [48]. b Overlay of ESI-QToF protein (blue trace, left $y$-axis) and ICP-QQQ ${ }^{32} \mathrm{~S}$ (red trace, right $y$-axis) chromatograms allowed peak correlation of ICP-QQQ and ESI-QToF spectra. The resolution (50000) and mass accuracy ( $0.2 \mathrm{ppm}$ ) of the ESI-QToF instrument employed allowed accurate protein identification by mass profiling, and the observed excellent peak patterns matching enabled correlating molecular peak identity and elemental $\mathbf{S}$ quantitation. Relation of the integrated mass flow peak areas results in sulfur quantification using the equation displayed in (c) panel. $C_{S}$, sulfur concentration in the sample; $C_{S p}$, sulfur concentration in the ${ }^{34} S$ spike; $W_{S}$ and $W_{S p}$, weighted mass of sample and spike, respectively; $A W_{S}$, sulfur atomic weight in the sample; $A W_{S p}$ sulfur atomic weight in the spike; $A_{S p,}^{a}{ }^{34} S$ abundance in the spike; $A_{S}^{b},{ }^{32} S$ abundance in the sample, $R_{M}$, the ${ }^{32} S /{ }^{34} S$ ratio in the mixture; $R_{S p}$, the ${ }^{32} \mathrm{~S} /{ }^{34} \mathrm{~S}$ ratio in the spike; and $\mathrm{R}_{\mathrm{S}}$, the ${ }^{32} \mathrm{~S} /{ }^{34} \mathrm{~S}$ ratio in the sample 
mixtures; electrospray ionization of the intact polypeptides to generate charged particle that can be manipulated and dissociated inside the mass spectrometer; high-resolution mass spectral data acquisition at precursor and fragment levels; and bioinformatic data processing by spectra searching/scoring against a species-specific database using various software tools to match the product ion dataset with the primary sequences of the proteins, including all modifications that affect their masses [58, 59].

After more than 20 years of mass spectrometrybased bottom-up proteomics, top-down proteome analysis is gaining momentum [60]. However, there are still limitations on front-end fractionation of complex mixtures and instrumentation-related challenges behind its implementation, particularly on high mass proteins [60]. Top-down venomics is in its infancy.
Only very recently reports on Ophiophagus hannah [61, 62] and Dendroaspis (angusticeps and polylepis) [63] venoms have proved that top-down venomics represents a fast and accurate tool for locus-specific assignment of many previously undetected protein species (iso- and proteoforms) of many known venom proteins, including the identification and precise location of acetylated lysine residues [63].

In comparison to bottom-up approaches, where offline pre-MS decomplexation of the venom proteome by RP-HPLC/SDS-PAGE represents the Rosetta Stone to quantify the venom components [55, 64] (Fig. 4a), topdown venomics offers the potential of simultaneously identifying and quantifying the whole venom proteome at protein species resolution using labeling strategies or label-free methods (Fig. 4b) [56, 65-68].

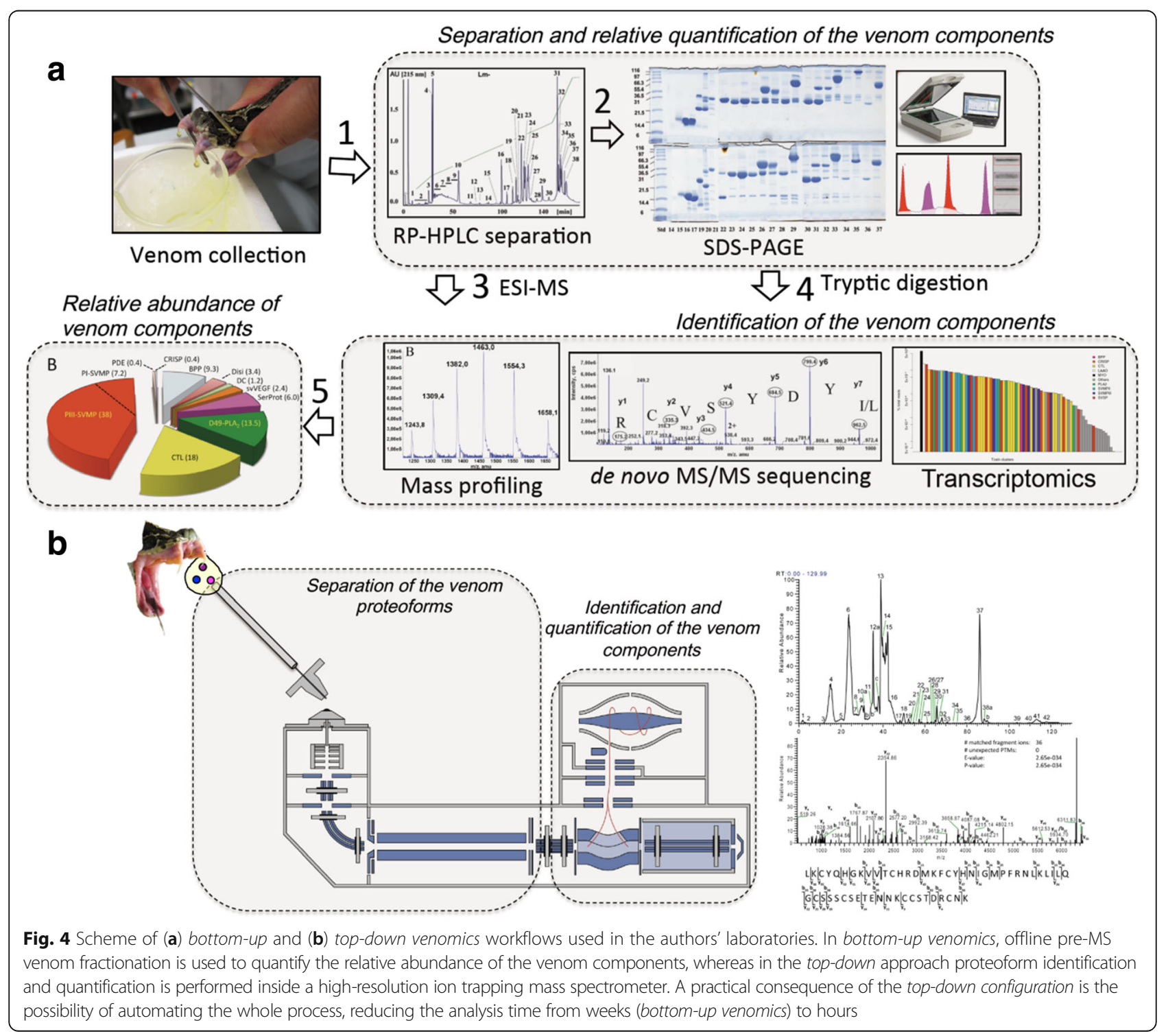




\section{A quick look through the glass}

Research on venoms has been continuously enhanced by advances in technology. The increased use of sensitive proteomics techniques over the last decade has revolutionized venomics research [69]. Achieving complete pre-ICP-MS separation and structural characterization of all the components of complex proteomes, such as snake venoms, represents an important challenge of contemporary venom analysis. Integrated with comprehensive venom gland transcriptomic and/or genomic datasets, novel computational tools for optimizing protein identification results, and with advances in MS instrumentation, dissociation strategies and bioinformatic tools, it is not unreasonable to speculate that top-down venomics approaches represent the cornerstone for achieving the challenging task of full description of venom proteomes [70-74].

Establishing the link between genotype and phenotype requires understanding the molecular basis of complex adaptive traits, such as venoms, which in turn demands both qualitative and quantitative comparisons of the temporal and spatial patterns of venom variation. The study of the geographic distribution of genetic variation within a species provides the basis for formulating hypotheses to explain the ecological processes responsible for the evolution of biodiversity, and to define the boundaries of species. Besides proving a molecular perspective for evolutionary studies on venoms, protein species-resolved absolute quantitative approaches will also have a great impact in other venomics disciplines such as toxicovenomics, ecological venomics, and antivenomics [75-83].

\section{Conclusions}

The application of next generation sequencing and high resolution mass spectrometry to study animal venoms has grown steadily in recent years, and quantitative locusresolved venom proteomes will increasingly be the goal of next-future venomics. In particular, the integration of topdown venomics, toxicovenomics, absolute quantitation, venom gland RNAseq and comparative snake genomics into a comprehensive evolutionary framework will revolutionize the field of molecular toxinology in the coming years. Understanding the natural history and evolutionary pressures that shaped the complexity of extant snake venoms is of applied importance for unveiling the molecular mechanisms that underlie venom variability, exploring the enormous potential of venoms as sources of chemical and pharmacological novelty, but also for the manufacture of novel, safer and more effective therapeutic antivenoms of broader therapeutic use [81, 83-85]. Clearly, implementing top-down and absolute quantification approaches into next-generation venomic workflows promises a quantitative leap in the study of venoms and a bright future to the field of integrative venomics [86].

\section{Abbreviations}

CCQM: Consultative Committee for Amount of Substance; CIPM: International Committee for Weights and Measures; ICAT: Isotope-coded affinity tag; ICP-MS: Inductively coupled plasma mass spectrometry; iTRAQ: Isobaric tag for relative and absolute quantification; LODs: Limits of detection; MeCAT: Metal-coded affinity tag; PRM: Parallel reaction monitoring; RPHPLC: Reversed-phase high-performance liquid chromatography; SRM: Selected reaction monitoring; TMTs: Tandem mass tags

\section{Acknowledgments}

Thanks are due to the many colleagues (particularly from the Laborarorio de Venómica Estructural y Funcional, Valencia, Spain; Instituto Clodomiro Picado, Costa Rica; Liverpool School of Tropical Medicine, Liverpool, UK; Ohio State University, Columbus, USA; and Australian Venom Research Unit, Melbourne, Australia) who, over the years, have provided, and continue providing, precious venoms and antivenoms within the framework of collaborative projects, and have contributed insights and suggestions through many stimulating discussions

\section{Funding}

Research at IBV-CSIC was supported by grant BFU2013-42833-P from the Ministerio de Economía y Competitividad, Madrid, Spain. F.C.C. acknowledges pre-doctoral fellowship from the Ministry of Economy and Competitiveness of Spain (BES-2014-068032).

Authors' contributions

All authors contributed to drafting and revising the manuscript. In addition, they all read and approved the final manuscript.

\section{Competing interests}

The authors declare that they have no competing interests.

Consent for publication

Not applicable.

Ethics approval and consent to participate

Not applicable.

\section{Publisher's Note}

Springer Nature remains neutral with regard to jurisdictional claims in published maps and institutional affiliations.

\section{Author details}

${ }^{1}$ Structural and Functional Venomics Laboratory, Instituto de Biomedicina de Valencia, C.S.I.C, Jaime Roig 11, 46010 Valencia, Spain. ${ }^{2}$ Skaggs School of Pharmacy \& Pharmaceutical Sciences, University of California-San Diego, La Jolla, CA, USA. ${ }^{3}$ Department of Physical and Analytical Chemistry, University of Oviedo, Oviedo, Spain. ${ }^{4}$ Instituto Clodomiro Picado, Facultad de Microbiología, Universidad de Costa Rica, San José, Costa Rica.

Received: 24 January 2017 Accepted: 19 April 2017

Published online: 28 April 2017

\section{References}

1. Galilei G. Discorsi e dimostrazioni matematiche, intorno a due nuove scienze. Leida: Apresso gli Elsevirri; 1638. ISBN 0-486-60099-8.

2. Whitehouse D. Renaissance genius: Galileo Galilei \& His Legacy to Modern Science. New York: Sterling Publishing; 2009. p. 1-219. ISBN 1-4027-6977-6.

3. Hawkins S. On the shoulder of giants. Philadelphia: Running Press; 2002. ISBN 9780762416981.

4. Breker M, Schuldiner M. The emergence of proteome-wide technologies: systematic analysis of proteins comes of age. Nat Rev Mol Cell Biol. 2014; 15(7):453-64.

5. McCloskey J. Mass spectrometry. USA: Methods Enzymol; 1990. p. 3-960.

6. Calvete JJ. The expanding universe of mass analyzer configurations for biological analysis. Methods Mol Biol. 2014;1072:61-81.

7. Han X, Aslanian A, Yates 3rd JR. Mass spectrometry for proteomics. Curr Opin Chem Biol. 2008;12(5):483-90.

8. Gygi SP, Rist B, Gerber SA, Turecek F, Gelb MH, Aebersold R. Quantitative analysis of complex protein mixtures using isotope-coded affinity tags. Nat Biotechnol. 1999;17(10):994-9. 
9. Eyers CE, Gaskell S, (editors). Quantitative proteomics. New Developments in Mass Spectrometry. Cambridge: RSC Publishing; 2014. ISBN 978-1-84973-808-8.

10. Rockman MV, Kruglyak L. Genetics of global gene expression. Nat Rev Genet. 2006;7(11):862-72

11. Aird SD, Watanabe Y, Villar-Briones A, Roy MC, Terada K, Mikheyev AS. Quantitative high-throughput profiling of snake venom gland transcriptomes and proteomes (Ovophis okinavensis and Protobothrops flavoviridis). BMC Genomics. 2013;14:790.

12. Sousa LF, Nicolau CA, Peixoto PS, Bernardoni JL, Oliveira SS, Portes-Junior $J A$, et al. Comparison of phylogeny, venom composition and neutralization by antivenom in diverse species of bothrops complex. PLoS Negl Trop Dis. 2013;7(9):e2442.

13. Nikolov M, Schmidt C, Urlaub H. Quantitative mass spectrometry-based proteomics: an overview. Methods Mol Biol. 2012;893:85-100.

14. Navarro P, Kuharev J, Gillet LC, Bernhardt OM, MacLean B, Röst HL, et al. A multicenter study benchmarks software tools for label-free proteome quantification. Nat Biotechnol. 2016;34(11):1130-6.

15. Elliott MH, Smith DS, Parker CE, Borchers C. Current trends in quantitative proteomics. J Mass Spectrom. 2009;44(12):1637-60

16. Ross PL, Huang YN, Marchese JN, Williamson B, Parker K, Hattan S, et al. Multiplexed protein quantitation in Saccharomyces cerevisiae using amine-reactive isobaric tagging reagents. Mol Cell Proteomics. 2004; 3(12):1154-69.

17. Ahrends R, Pieper S, Neumann B, Scheler C, Linscheid MW. Metal-coded affinity tag labeling: a demonstration of analytical robustness and suitability for biological applications. Anal Chem. 2009;81(6):2176-84.

18. Zhang H, Yan W, Aebersold R. Chemical probes and tandem mass spectrometry: a strategy for the quantitative analysis of proteomes and subproteomes. Curr Opin Chem Biol. 2004;8(1):66-75.

19. Bantscheff M, Lemeer S, Savitski MM, Kuster B. Quantitative mass spectrometry in proteomics: critical review update from 2007 to the present. Anal Bioanal Chem. 2012:404(4):939-65.

20. Prange A, Pröfrock D. Chemical labels and natural element tags for the quantitative analysis of bio-molecules. J Anal At Spectrom. 2008:23(4):432-59.

21. Julka S, Regnier F. Quantification in proteomics through stable isotope coding: a review. J Proteome Res. 2004;3(3):350-63.

22. Yao X, Freas A, Ramirez J, Demirev PA, Fenselau C. Proteolytic 180 labeling for comparative proteomics: model studies with two serotypes of adenovirus. Anal Chem. 2001;73(13):2836-42.

23. Staes A, Demol H, Van Damme J, Martens L, Vandekerckhove J, Gevaert K. Global differential non-gel proteomics by quantitative and stable labeling of tryptic peptides with oxygen-18. J Proteome Res. 2004;3(4):786-91.

24. Thompson A, Schäfer J, Kuhn K, Kienle S, Schwarz J, Schmidt G, et al. Tandem mass tags: a novel quantification strategy for comparative analysis of complex protein mixtures by MS/MS. Anal Chem. 2003;75(8):1895-904.

25. Galan JA, Guo M, Sanchez EE, Cantu E, Rodriguez-Acosta A, Perez JC, et al. Quantitative analysis of snake venoms using soluble polymer-based isotope labeling. Mol Cell Proteomics. 2008;7(4):785-99.

26. Zelanis A, Tashima AK, Pinto AF, Paes Leme AF, Stuginski DR, Furtado MF, et al. Bothrops jararaca venom proteome rearrangement upon neonate to adult transition. Proteomics. 2011;11(21):4218-28.

27. Gao JF, Qu YF, Zhang XQ, He Y, Ji X. Neonate-to-adult transition of snake venomics in the short-tailed pit viper, Gloydius brevicaudus. J Proteomics. 2013;84:148-57.

28. Mann M. Functional and quantitative proteomics using SILAC. Nat Rev Mol Cell Biol. 2006;7(12):952-8.

29. Kettenbach AN, Rush J, Gerber SA. Absolute quantification of protein and post-translational modification abundance with stable isotope-labeled synthetic peptides. Nat Protoc. 2011;6(2):175-86.

30. Beynon RJ, Doherty MK, Pratt JM, Gaskell SJ. Multiplexed absolute quantification in proteomics using artifical QCAT proteins of concatenated signature peptides. Nat Methods. 2005;2(8):587-9.

31. Brun V, Masselon C, Garin J, Dupuis A. Isotope dilution strategies for absolute quantitative proteomics. J Proteomics. 2009;72(5):740-9.

32. Villanueva J, Carrascal M, Abian J. Isotope dilution mass spectrometry for absolute quantification in proteomics: concepts and strategies. J Proteomics. 2014;96:184-99.

33. Alonso Jl, González P. Isotope dilution mass spectrometry. Cambridge: RSC Publishing; 2013. ISBN 978-1-84973-333-5.

34. Hevesy GV, Paneth F. Die Löslichkeit des Bleisulfids und Bleichromats. Z Anorg Allg Chem. 1913;82(1):323-8.
35. Pan S, Aebersold R, Chen R, Rush J, Goodlett DR, McIntosh MW, et al. Mass spectrometry based targeted protein quantification: methods and applications. J Proteome Res. 2009;8(2):787-97.

36. Keerthikumar S, Mathivanan S. Proteotypic peptides and their applications. Methods Mol Biol. 2017;1549:101-7.

37. Lange V, Picotti P, Domon B, Aebersold R. Selected reaction monitoring for quantitative proteomics: a tutorial. Mol Syst Biol. 2008;4:222.

38. Bourmaud A, Gallien S, Domon B. Parallel reaction monitoring using quadrupole-Orbitrap mass spectrometer: Principle and applications. Proteomics. 2016;16(15-16):2146-59.

39. Gillet LC, Leitner A, Aebersold R. Mass spectrometry applied to bottom-up proteomics: entering the high-throughput era for hypothesis testing. Annu Rev Anal Chem (Palo Alto Calif). 2016;9(1):449-72.

40. Houk RS, Fassel VA, Flesch GD, Svec HJ, Gray AL, Taylor CE. Inductively coupled argon plasma as an ion source for mass spectrometric determination of trace elements. Anal Chem. 1980;53(14):2283-9.

41. Becker JS. Inorganic Mass Spectrometry: principles and applications. Chichester: John Wiley \& Sons Ltd; 2007. p. 118-76. ISBN 978-0-470-01200-0.

42. Bettmer J, Montes-Bayón M, Ruiz Encinar J, Fernández-Sánchez ML, Fernández de la Campa M del R, Sanz-Medel A. The emerging role of ICP-MS in proteomic analysis. J Proteomics. 2009;72(6):989-1005.

43. Sanz-Medel A, Montes-Bayón M, Jörg Bettmer M, Fernández-Sánchez ML, Ruiz Encinar J. ICP-MS for absolute quantification of proteins for heteroatom-tagged, targeted proteomics. Trends Anal Chem. 2012;40:52-63.

44. Reeks TA, Fry BG, Alewood PF. Privileged frameworks from snake venom. Cell Mol Life Sci. 2015;72(10):1939-58.

45. Calvete JJ, Juárez P, Sanz L. Snake venomics. Strategy and applications. J Mass Spectrom. 2007;42(11):1405-14.

46. Rappel C, Schaumlöffel D. The role of sulfur and sulfur isotope dilution analysis in quantitative protein analysis. Anal Bioanal Chem. 2008;390(2):605-15.

47. Diez Fernández S, Sugishama N, Ruiz Encinar J, Sanz-Medel A. Triple quad ICPMS (ICPQQQ) as a new tool for absolute quantitative proteomics and phosphoproteomics. Anal Chem. 2012;84(14):5851-7.

48. Calderón-Celis F, Diez-Fernández S, Costa-Fernández JM, Ruiz Encinar J, Calvete JJ, Sanz-Medel A. Elemental mass spectrometry for absolute intact protein quantification without protein-specific standards: application to snake venomics. Anal Chem. 2016;88(19):9699-706.

49. Petras D, Sanz L, Segura A, Herrera M, Villalta M, Solano D, et al. Snake venomics of African spitting cobras: toxin composition and assessment of congeneric cross-reactivity of the pan-African EchiTAb-Plus-ICP antivenom by antivenomics and neutralization approaches. J Proteome Res. 2011;10(3):1266-80.

50. Lomonte B, Calvete JJ. Strategies in 'snake venomics' aiming at an integrative view of compositional, functional, and immunological characteristics of venoms. J Venom Anim Toxins Incl Trop Dis. 2017;23. doi: 10.1186/s40409-017-0117-8.

51. Schlüter $H$, Apweiler $R$, Holzhütter HG, Jungblut PR. Finding one's way in proteomics: a protein species nomenclature. Chem Cent J. 2009;3:11.

52. Smith LM, Kelleher NL, Consortium for Top Down Proteomics. Proteoform: a single term describing protein complexity. Nat Methods. 2013;10(3):186-7.

53. Jungblut PR, Thiede B, Schlüter H. Towards deciphering proteomes via the proteoform, protein speciation, moonlighting and protein code concepts. J Proteomics. 2016;134:1-4.

54. Brahma RK, McCleary RJ, Kini RM, Doley R. Venom gland transcriptomics for identifying, cataloging, and characterizing venom proteins in snakes. Toxicon. 2015:93:1-10

55. Eichberg S, Sanz L, Calvete JJ, Pla D. Constructing comprehensive venom proteome reference maps for integrative venomics. Expert Rev Proteomics. 2015;12(5):557-73

56. Toby TK, Fornelli L, Kelleher NL. Progress in top-down proteomics and the analysis of proteoforms. Annu Rev Anal Chem (Palo Alto Calif). 2016;9(1):499-519.

57. Ryan CM, Souda P, Halgand F, Wong DT, Loo JA, Faull KF, et al. Confident assignment of intact mass tags to human salivary Cystatins using top-down Fourier-transform ion cyclotron resonance mass spectrometry. J Am Soc Mass Spectrom. 2010;21(6):908-17.

58. Guner H, Close PL, Cai W, Zhang H, Peng Y, Gregorich ZR, et al. MASH Suite: a user-friendly and versatile software interface for high-resolution mass spectrometry data interpretation and visualization. J Am Soc Mass Spectrom. 2014;25(3):464-70.

59. Fellers RT, Greer JB, Early BP, Yu X, LeDuc RD, Kelleher NL, et al. ProSight Lite: graphical software to analyze top-down mass spectrometry data. Proteomics. 2015;15(7):1235-8. 
60. Compton PD, Zamdborg L, Thomas PM, Kelleher NL. On the scalability and requirements of whole protein mass spectrometry. Anal Chem. 2011;83(17): 6868-74.

61. Petras $D$, Heiss $P$, Süssmuth $R D$, Calvete JJ. Venom proteomics of Indonesian king cobra, Ophiophagus hannah: integrating top-down and bottom-up approaches. J Proteome Res. 2015;14(6):2539-56.

62. Melani RD, Skinner OS, Fornelli L, Domont GB, Compton PD, Kelleher NL. Mapping proteoforms and protein complexes from king cobra venom using both denaturing and native top-down proteomics. Mol Cell Proteomics. 2016;15(7):2423-34.

63. Petras D, Heiss PMN, Harrison RA, Süssmuth RD, Calvete JJ. Top-down venomics of the East African green mamba, Dendroaspis angusticeps, and the black mamba, Dendroaspis polylepis, highlight the complexity of their toxin arsenals. J Proteomics. 2016;146:148-64.

64. Calvete JJ. Next-generation snake venomics: protein-locus resolution through venom proteome decomplexation. Expert Rev Proteomics. 2014; 11(3):315-29.

65. Wiener MC, Sachs JR, Deyanova EG, Yates NA. Differential mass spectrometry: a label-free LC-MS method for finding significant differences in complex peptide and protein mixtures. Anal Chem. 2004;76(20):6085-96.

66. Hung CW, Tholey A. Tandem mass tag protein labeling for top-down identification and quantification. Anal Chem. 2012;84(1):161-70.

67. Wu S, Brown JN, Tolic N, Meng D, Liu X, Zhang H, et al. Quantitative analysis of human salivary gland-derived intact proteome using top-down mass spectrometry. Proteomics. 2014;14(10):1211-22.

68. Geis-Asteggiante L, Ostrand-Rosenberg S, Fenselau C, Edwards NJ. Evaluation of spectral counting for relative quantitation of proteoforms in top-down proteomics. Anal Chem. 2016;88(22):10900-7.

69. Calvete JJ. Snake venomics: from the inventory of toxins to biology. Toxicon. 2013;75:44-62.

70. Tran JC, Zamdborg L, Ahlf DR, Lee JE, Catherman AD, Durbin KR, et al. Mapping intact protein isoforms in discovery mode using top-down proteomics. Nature. 2011;480(7376):254-8.

71. Cai W, Guner H, Gregorich ZR, Chen AJ, Ayaz-Guner S, Peng Y, et al. MASH Suite Pro: A comprehensive software tool for top-down proteomics. Mol Cell Proteomics. 2016;15(2):703-14.

72. Gault J, Malosse C, Machata S, Millien C, Podglajen I, Ploy MC, et al. Complete posttranslational modification mapping of pathogenic Neisseria meningitidis pilins requires top-down mass spectrometry. Proteomics. 2014; 14(10):1141-51.

73. Li Y, Compton PD, Tran JC, Ntai I, Kelleher NL. Optimizing capillary electrophoresis for top-down proteomics of 30-80 kDa proteins. Proteomics. 2014;14(10):1158-64.

74. Cannon JR, Cammarata MB, Robotham SA, Cotham VC, Shaw JB, Fellers RT, et al. Ultraviolet photodissociation for characterization of whole proteins on a chromatographic time scale. Anal Chem. 2014;86(4):2185-92.

75. Lauridsen LP, Laustsen AH, Lomonte B, Gutiérrez JM. Toxicovenomics and antivenom profiling of the Eastern green mamba snake (Dendroaspis angusticeps). J Proteomics. 2016;136:248-61.

76. Lauridsen LP, Laustsen AH, Lomonte B, Gutiérrez JM. Exploring the venom of the forest cobra snake: Toxicovenomics and antivenom profiling of Naja melanoleuca. J Proteomics. 2017;150:98-108.

77. Diz AP, Martínez-Fernández M, Rolán-Alvarez E. Proteomics in evolutionary ecology: linking the genotype with the phenotype. Mol Ecol. 2012;21(5):1060-80.

78. Sunagar K, Morgenstern D, Reitzel AM, Moran Y. Ecological venomics: How genomics, transcriptomics and proteomics can shed new light on the ecology and evolution of venom. J Proteomics. 2016;135:62-72.

79. Diz AP, Calvete JJ. Ecological proteomics: is the field ripe for integrating proteomics into evolutionary ecology research? J Proteomics. 2016;135:1-3.

80. Calvete JJ. The challenge of integrating proximate and ultimate causes to reconstruct the natural histories of venoms: the evolutionary link. Expert Rev Proteomics. 2016;13(12):1059-61.

81. Calvete JJ. Venomics: integrative venom proteomics and beyond. Biochem J. 2017:474(5):611-34.

82. Lomonte B, Fernández J, Sanz L, Angulo Y, Sasa M, Gutiérrez JM, et al. Venomous snakes of Costa Rica: biological and medical implications of their venom proteomic profiles analyzed through the strategy of snake venomics. J Proteomics. 2014;105:323-39.

83. Calvete JJ, Sanz L, Pla D, Lomonte B, Gutiérrez JM. Omics meets biology: application to the design and preclinical assessment of antivenoms. Toxins. 2014;6(12):3388-405
84. Williams DJ, Gutiérrez JM, Calvete JJ, Wüster W, Ratanabanangkoon K, Paiva $\mathrm{O}$, et al. Ending the drought: new strategies for improving the flow of affordable, effective antivenoms in Asia and Africa. J Proteomics. 2011;74(9):1735-67.

85. Gutiérrez JM, Burnouf T, Harrison RA, Calvete JJ, Kuch U, Warrell DA, et al. A multicomponent strategy to improve the availability of antivenom for treating snakebite envenoming. Bull World Health Organ. 2014;92:526-32.

86. Calvete JJ, Lomonte B. A bright future for integrative venomics. Toxicon. 2015:107(Pt B):159-62

\section{Submit your next manuscript to BioMed Central and we will help you at every step:}

- We accept pre-submission inquiries

- Our selector tool helps you to find the most relevant journal

- We provide round the clock customer support

- Convenient online submission

- Thorough peer review

- Inclusion in PubMed and all major indexing services

- Maximum visibility for your research

Submit your manuscript at www.biomedcentral.com/submit

) Biomed Central 